\title{
Cognitive and school functioning in children and adolescents with chronic pain: A critical review
}

\author{
Bruce D Dick PhD ${ }^{1}$, Rebecca Pillai Riddell $\mathrm{PhD}^{2}$
}

BD Dick, R Pillai Riddell. Cognitive and school functioning in children and adolescents with chronic pain: A critical review. Pain Res Manage 2010;15(4):238-244.

Cognitive function is a critical factor related to a child's overall developmental trajectory. There is increasing evidence that chronic pain disrupts cognitive function in adults. Little is known about the nature or impact of cognitive disruption in children and adolescents with chronic pain. The present review examines the current literature related to cognitive function in children and adolescents with chronic pain, implications of these findings and future research directions. Nine studies on this topic were found, with a relatively recent increase in publications related to school attendance and subjective studies of school performance. The studies that were found on this topic suggested that chronic pain affects cognitive function in children but the scope of these effects on children's function and developmental trajectories is not yet clear. While methodological issues surely make it difficult to study cognitive function in children with chronic pain, the potential gains from such research warrant a pursuit of such work. Much remains to be studied on this important topic.

Key Words: Adolescents; Children; Chronic pain; Cognitive function; Pediatric; School

$\mathrm{P}$ ediatric chronic pain is a prevalent and significant major health issue (1). The potential costs to the individual child with chronic pain, the child's family and to society, using both short- and long-term analyses, are enormous (2,3). Chronic pain is increasingly being recognized as a unique medical problem in its own right rather than merely a symptom secondary to a medical disorder (4). The effects of chronic pain on a child's daily activities, quality of life and developmental trajectory are complex. Pain-related disability is common and has been recognized in the scientific literature as a unique disorder (painassociated disability syndrome [PADS]) (5). The studies considered in the present review include, but are not limited to, individuals and clinical populations identified as displaying the clinical features of PADS. Research has pointed to multiple factors that contribute to PADS including pain levels, sleep disturbance, deconditioning, mood disturbance, fear of pain and catastrophizing. The relationships between these factors are proposed to be highly intertwined over time, such that the direction of causation becomes difficult to discern (4). Cognitive disruption has been recognized as an important component of PADS (5), in which it has been described as a factor that contributes to pain-related disability. While acknowledging the importance of this factor, it has simultaneously been recognized that there is a paucity of well-designed studies on this important topic.

Cognitive function refers to a broad range of processes performed by the brain. These processes include, but are not

\section{Fonctionnement cognitif et scolaire des enfants et adolescents souffrant de douleur chronique : Revue critique}

Le fonctionnement cognitif est un facteur crucial dans le développement global de l'enfant. Les preuves s'accumulent selon lesquelles la douleur chronique perturbe le fonctionnement cognitif chez l'adulte. On en sait peu sur la nature ou l'impact des perturbations cognitives chez les enfants et adolescents souffrant de douleur chronique. La présente revue se penche sur la littérature actuelle relativement au fonctionnement cognitif des enfants et des adolescents qui souffrent de douleur chronique, sur les implications de ces découvertes et les orientations futures de la recherche. Neuf études ont été recensées à ce sujet et on note une augmentation des publications récentes sur la fréquentation scolaire et l'évaluation subjective du rendement scolaire. Les études recensées donnent à penser que la douleur chronique affecte le fonctionnement cognitif des enfants, mais l'ampleur de ces effets sur le fonctionnement et le développement des enfants n'est pas entièrement élucidé. Bien que les questions d'ordre méthodologique compliquent sans contredit l'étude du fonctionnement cognitif des enfants souffrant de douleur chronique, les gains potentiels d'une telle recherche justifient qu'on aille de l'avant. Cet important domaine reste largement inexploré.

limited to, activities such as perception, information processing, learning, attention, memory, decision making, planning, inference and abstraction. The disruption of cognitive function by pain refers to the ability of pain to interrupt and/or interfere with one or more of these processes. The heretofore most commonly studied functions shown to be disrupted by pain have been examined primarily in adult populations. The most commonly cited disrupted cognitive processes have been attention and memory (6). These are just a few of the critical cognitive variables that may negatively affect learning and academic performance in this clinical population. In the present review, we will focus on cognitive performance and academic functioning.

In addition to the above factors, other researchers $(7,8)$ have highlighted the importance of school attendance and the common outcome of high absence rates in children with chronic pain. School functioning refers to a wide range of factors including school attendance, academic achievement and social relationships. While school attendance has been addressed to some extent in the literature $(9,10)$, less is known about how chronic pain impacts cognitive functioning in children with chronic pain. Given the importance of cognitive development as part of a child's lifelong developmental trajectory, the present comprehensive review was conducted to synthesize the existing literature on cognitive function in pediatric chronic pain populations.

The magnitude of the school attendance problem was addressed by Stang and Osterhaus (10). They estimated that in

${ }^{1}$ Departments of Anesthesiology and Pain Medicine $\mathcal{E}$ Psychiatry, University of Alberta, and Stollery Children's Hospital, Edmonton, Alberta;

${ }^{2}$ Department of Psychology, York University, and Psychiatry Research, Hospital for Sick Children, Toronto, Ontario

Correspondence: Dr Bruce D Dick, Department of Anesthesiology and Pain Medicine, 8-120 Clinical Sciences Building, University of Alberta,

Edmonton, Alberta T6G 2G3. Telephone 780-407-1097, fax 780-407-7461, e-mail bruce.dick@ualberta.ca 
the United States, thousands of children miss multiple school days each month as a result of headaches alone. Moreover, Sato et al (9) provided an excellent review of school-related issues in children with chronic pain, emphasizing them as integral factors to consider when developing a treatment plan. They highlighted the critical importance of the school environment and school experiences in fostering independence and identity development as well as social relationships with other children and adults (11). They discussed the concept of 'risk periods' that are often age related, in which key developmental tasks associated with the school environment and academic performance can be critical. They also pointed out vicious cycles that can occur in a child's life due to school difficulties related to falling behind in school work (12) and family disruption (13). It is clear that missing school can be a significant issue for children with chronic pain.

However, what appears to be lacking in these articles is a discussion of the potential that lost learning time - a key factor in suboptimal coping with chronic pain (14) - could be related to cognitive disruptions. One potential pathway could involve a child's pain either directly interrupting or indirectly impacting how he or she attends to, stores or retrieves information. This difficulty could then lead to school absences due to frustration over not being able to process and keep up with academic material and demands. Moreover, given the potential that a child may be less intellectually stimulated at home than at school, it appears logical to suggest that over time, as a child stays out of school, this may also be an additional pathway contributing negatively to a child's cognitive development. Given the hypothesized link between cognitive function and some of the most maladaptive psychosocial outcomes of pediatric chronic pain, the current review sets out to gather and synthesize the existing data relating to academic and/or cognitive functioning in children with chronic pain. Our primary objective is to review and synthesize the existing literature on this often neglected but very important topic and highlight areas of need for future research.

\section{METHOD}

Key databases were searched for articles in peer-reviewed journals within the past 20 years (MEDLINE, EMBASE, PsycINFO, ERIC, CINAHL, Cochrane Central Register of Controlled Trials and Cochrane Database of Systematic Reviews) by an individual specifically trained in searches for literature reviews. A second literature search was later conducted by one of the authors (BDD) to ascertain whether any other relevant articles had been published after the original search was conducted and also to examine whether any relevant publications had been missed in the original search. Search terms were chosen by consensus among a group of pain researchers based on the existing research literature and clinical experience. These included broad terms related to health and development such as pain, chronic pain, psychological function, mental health, coping, emotions, emotional adjustment, stress, coping behaviour, quality of life, disability, children and adolescents. Terms related to cognition included cognitive function, cognitive impairment, attention, memory, academic performance, academic achievement and school attendance. School attendance was selected solely to determine whether any of these articles discussed academic performance. Articles that focused solely on school attendance were not considered germane to the current review. For each database, the number of studies found, the number meeting inclusion criteria and the number excluded were tracked.

A research assistant previously trained in the literature search and selection protocol performed an initial screening of all articles identified in the original search using study titles and abstracts. Key information was extracted by this research assistant using a standardized form based on other similar published comprehensive reviews. Factors extracted using this form included research design and methodology; results for each study were organized and categorized within a database spreadsheet, and were used in the final decisions regarding inclusion or exclusion. Factors evaluated at each stage of review by all involved reviewers included target population, age range of participants, sex, pain diagnoses, study design, sample size, main outcome measures, overall findings and the general domain category relevant to the main outcome (eg, cognitive function and academic performance). The titles and abstracts of all initially identified publications were reviewed in detail to exclude reviews and nonempirical publications.

A reliability check was performed (30\% being checked) by a primary investigator (RPR). Again, at this stage, for each database, the number of studies identified, the number of studies meeting inclusion criteria and the number of excluded studies were tracked.

Eligible studies identified in the initial screening were then reviewed by a primary investigator (BDD) to determine suitability for a full review of the articles. Relevance to the identified research area and the methodological merit were evaluated in each identified study.

\section{RESULTS}

Initially, 1887 studies of interest were identified as potentially relevant. The reliability check conducted found a high level of compliance (greater than 95\%) with search methods outlined a priori. Of the originally identified studies, the full articles for 238 studies were selected and reviewed for relevance by the authors. Of the 238 studies, 45 were identified as focusing on the effects of chronic pain on cognitive function, school performance or school attendance. However, the majority of studies focused on school attendance rates with no handling of either cognitive functioning or academic performance. Only nine studies examined cognitive functioning or academic performance in pediatric chronic pain patients. While different reporting methods made a meta-analysis impossible, it was determined that the articles could be systematically reviewed and synthesized according to four broad areas. These subareas were physiological indicators, cognitive/academic testing, selfand proxy-report studies, and studies of attention and memory bias. Synthesizing the literature by subarea was deemed appropriate for a more useful analysis and inventory of articles exploring the impact of pediatric chronic pain on cognitive function. A summary of all nine articles is presented in Table 1.

Physiological indicators of cognitive (attentional) disruption A few studies have measured the effects of chronic pain on cognitive function using physiological indexes. Zohsel et al (15) 


\section{TABLE 1}

\section{Chronic pain and cognitive function}

\begin{tabular}{|c|c|c|c|}
\hline Study & Sample & Variables and measures & Main outcomes \\
\hline $\begin{array}{l}\text { Zohsel et al, } \\
2008 \text { (15), } \\
\text { significant } \\
\text { study }\end{array}$ & $\begin{array}{l}\mathrm{n}=30 \text { children (with } \\
\text { migraine, } \mathrm{n}=15 ; \\
\text { controls, } \mathrm{n}=15) \\
\text { Sex: } 15 \text { girls ( } 7 \text { with } \\
\text { migraine; } 8 \text { controls) }\end{array}$ & $\begin{array}{l}\text { ERPs: Somatosensory N150 } \\
\text { amplitude and latency, } \\
\text { somatosensory P260 amplitude } \\
\text { and latency, somatosensory } \\
\text { P300 amplitude and latency, }\end{array}$ & $\begin{array}{l}\text { Significant association. In response to painful and nonpainful stimuli, children with } \\
\text { migraines showed larger somatosensory } \mathrm{P} 300 \text { amplitudes (group: } F[1,28]=6.90 \text {, } \\
\mathrm{P}<0.05 \text {; group } \times \text { intensity: } \mathrm{P}>0.2 \text { ) and shorter somatosensory } \mathrm{P} 300 \text { latency } \\
\text { (group: } \mathrm{F}[1,28]=15.54, \mathrm{P}<0.011 \text {; group } \times \text { intensity: } \mathrm{P}>0.8 \text { ) }\end{array}$ \\
\hline
\end{tabular}

Age range: $10-15$ years

Logan et al, $\quad \mathrm{n}=220$ adolescents with 2008 (24), chronic pain significant Sex: $79.8 \%$ females study Mean age (range): 14.7 years (12-17 years)

Ho et al, 2008 (19) significant Sex: 46 females study Mean age (range): 14.64 years (8-18 years)

Buodo et al, $n=36$ children (with 2004 (16), migraine, $\mathrm{n}=18$; significant controls, $\mathrm{n}=18$ ) study

Sex: 17 females (10 with migraine; 7 controls)

Mean age (range): With migraine, $10.6 \pm 2.1$ years (8-14 years); controls, $10.7 \pm 2$ years (8-14 years)

Boyer et al, $\quad n=59$ children with 2006 (25), recurrent abdominal significant pain study Sex: 33 girls Mean age (range): 12.59 years (9-17 years)

Koutantji $\quad n=36$ children (children et al, with musculoskeletal 1999 (26), pain, $n=18$; control significant group, $\mathrm{n}=18$ ) study P300 amplitude and latency, auditory P300 amplitude and latency; VAS (rating perceived stimulus intensity)

Pain/school attendance/academic performance (VAS). Academic competence: Self-Perception Profile for Adolescents, WalkerMcConnell Scale of Social Competence and School Adjustment

Cognitive ability: WISC-III and WISC-IV, Wechsler Adult Intelligence Scale III. Academic achievement: WRAT-3, GORT-3, GORT-4, Test of Written Language 3, Wechsler Individual Achievement Test II

Electroencephalogram recorded from three sites: Fz, Cz and Pz. ERPs: N100 amplitude and latency (target and standard stimulus type), and P300 amplitude and latency (target and standard stimulus type). Reaction times: Acoustic oddball paradigm

Dot-probe task; Abdominal Pain Index; Body Vigilance Scale; Child Behavior Checklist

Significant association. Decreased academic performance: $44.3 \%$ of parents reported a decline in their adolescent's grades since the onset of pain. Chronic pain and school attendance: $44 \%$ of students with chronic pain missed at least $25 \%$ of school days, and $20 \%$ missed more than one-half of school days; adolescents with neuropathic pain had significantly better school attendance than participants with nonmigraine headaches (mean $[ \pm \mathrm{SD}$ ] difference $0.19 \pm 0.07$, $\mathrm{P}<0.05$ ) or functional abdominal pain (mean difference $0.27 \pm 0.09, \mathrm{P}<0.05$ )

Significant association. Cognitive functioning compared with the general population: Chronic pain participants showed higher mean scores in general intelligence ( $z=4.95, P<0.000001)$, verbal intelligence $(z=5.18, P<0.000001)$, performance intelligence $(z=3.49, P<0.0005)$, verbal comprehension $(z=6.16, P<0.000001)$, perceptual organization $(z=4.18, P<0.00005)$ and processing speed $(z=2.82$, $P<0.005)$. No significant differences were seen in working memory $(z=0.92)$. Academic achievement scores compared with the general population: Chronic pain participants showed higher mean scores in word reading $(z=4.31$, $\mathrm{P}<0.00005)$ and mathematical reasoning $(\mathrm{z}=2.70, \mathrm{P}<0.01)$. No significant differences were seen in reading comprehension $(z=1.82)$, arithmetic computation $(z=0.05)$, spelling $(z=2.27)$ or written expression $(z=2.51)$

Significant association. Group differences: Smaller N100 amplitude to standard stimuli in children with migraines; significant amplitude difference between standard and target N100 in children with migraines; target P300 amplitude habituated in children with migraines, but not in control subjects. Group-stimulus interaction $(F[1,34]=3.18, P<0.08)$ : P300 latency for frequent stimuli longer in children with migraines; significant positive correlation between reaction times and target P300 latency in children with migraines

Significant association. Attentional bias: A three-way interaction found for threat word position, dot probe position and exposure position $(F[1,56]=4.44, P<0.05)$. Within subliminal condition, participants responded faster when dot probes replaced the threat word of the threat-neutral word pairs and responded slower when dot probes replaced the neutral word of the threat-neutral word pairs. Reversed pattern appeared in supraliminal condition (participants avoiding threat words in this condition). Biases toward supraliminally presented social threat words negatively correlated with both biases toward subliminally presented pain words $(r=-0.30, P<0.05)$ and attentional biases toward subliminally presented social threat words $(r=-0.29, P<0.05)$. Biases to attend to supraliminally presented pain words were negatively associated with parents' reports of child's abdominal pain $(r=-0.31, P<0.05)$ but positively correlated with parents' reports of children's anxiety/depression $(r=0.36, P<0.05)$. Biases to attend to subliminally presented social threat words positively correlated with children's reports of body vigilance $(r=0.32, P<0.05)$ and abdominal pain $(r=0.35, P<0.05)$, and marginally correlated with parent-reported somatic complaints $(r=0.28, P<0.10)$

VAS (rating various aspects of pain Significant association. Recall scores: Difference on recall between groups only for experience); McGill Pain Questionnaire; processing memory task (2 recall lists) words encoded in the self-reference condition $(F[1,34]=3.75$, exact $P=0.061)$; pain group (mean $0.31 \pm 0.14$ ) recalling more information encoded in the self-reference condition than control group (mean $0.23 \pm 0.12$ ); significant effect of reference condition for pain group on recall of sensory words $(F[1,34]=6.71, P<0.05)$ but not for control group; sensory words in self-reference condition in pain group better recalled than other reference encoding (self-reference mean $0.42 \pm 0.19$, other reference mean $0.26 \pm 0.20$ ); significant differences between groups for reference condition on recall of neutral $(F[1,34]=4.19, P<0.05)$ and sensory words $(F[1,34]=8.46, P<0.05)$, but not for affective words $(F[1,34]<1)$; main effect of word type significant $(F[2,68]=3.63, P<0.05)$; significant difference in recall of sensory words compared with recall of affective words with increased recall of sensory words $(F[1,34]=3.63, P<0.05)$ (neutral words, mean $0.24 \pm 0.14$; sensory words, mean 0.31 \pm 0.13 ; affective words, mean 0.25 \pm 0.14$)$. Processing time: Significant interaction by word type $(F[2,68]=3.93, P<0.05)$; group by reference interaction for sensory words $(F[1,34]=3.65$, exact $P=0.064)$; pain group spent less time processing sensory information in self-reference condition than control group $(F[1,35]=3.60$, exact $P=0.066)$ 
TABLE 1 - CONTINUED

Chronic pain and cognitive function

\begin{tabular}{|c|c|c|c|}
\hline Study & Sample & Variables and measures & Main outcomes \\
\hline $\begin{array}{l}\text { Sherry et al, } \\
1991(17), \\
\text { significant } \\
\text { study }\end{array}$ & $\begin{array}{l}\mathrm{n}=100 \text { children with } \\
\text { musculoskeletal pain } \\
\text { Sex: } 76 \text { females } \\
\text { Age range: } 3-20 \text { years }\end{array}$ & $\begin{array}{l}\text { WISC - Revised; WRAT - } \\
\text { Revised; Woodcock-Johnson } \\
\text { Psychoeducational Battery; } \\
\text { VAS (mothers rated patient's } \\
\text { overall state of health) }\end{array}$ & $\begin{array}{l}\text { Significant association. Of the } 62 \text { children tested, all were found to have full-scale } \\
\text { IQ scores in the average range. Seven children with IQ scores in the average } \\
\text { range were reported to have low school achievements tests. No data were } \\
\text { provided regarding the extent of those deficits }\end{array}$ \\
\hline $\begin{array}{l}\text { Haverkamp } \\
\text { et al, } \\
2002 \text { (18), } \\
\text { significant } \\
\text { study }\end{array}$ & $\begin{array}{l}\mathrm{n}=54 \text { children (with } \\
\text { migraines, } \mathrm{n}=37 ; \\
\text { healthy siblings, } \mathrm{n}=17 \text { ) } \\
\text { Sex: } 26 \text { females ( } 15 \text { with } \\
\text { migraines; } 11 \text { healthy } \\
\text { siblings) } \\
\text { Mean age: With migraines, } \\
10 \pm 2.10 \text { years; healthy } \\
\text { siblings, } 8.81 \pm 2.61 \text { years }\end{array}$ & $\begin{array}{l}\text { Kaufman-Assessment Battery for } \\
\text { Children, which includes two } \\
\text { cognitive scales: SEQ and SIM. } \\
\text { Results of both scales } \\
\text { summarized to total scale of } \\
\text { mental performance composite } \\
\end{array}$ & $\begin{array}{l}\text { Significant association. Memory: Children with migraines performed relatively worse } \\
\text { in test items requiring memory abilities (as assessed by the SEQ). Significant } \\
\text { difference between SEQ and SIM only in children without siblings and control } \\
\text { group. No differences in children with migraines simultaneously having a sibling }\end{array}$ \\
\hline $\begin{array}{l}\text { Bell et al, } \\
1994(20), \\
\text { non- } \\
\text { significant } \\
\text { study }\end{array}$ & $\begin{array}{l}\mathrm{n}=8 \text { with fibromyalgia } \\
\text { syndrome (group I) } \\
\text { Sex: } 8 \text { girls } \\
\text { Mean age: } 12.45 \text { years }\end{array}$ & $\begin{array}{l}\text { VAS (rating } 12 \text { common } \\
\text { symptoms) }\end{array}$ & Cognitive dysfunction $6.75 / 10$; muscle pain $8.5 / 10$ \\
\hline
\end{tabular}

directly measured cognitive function in a group of children and adolescents with chronic pain. Using event-related brain potentials (ERPs), they examined brain response components linked to conscious attention to nonpainful stimuli as well as sensory responses to nonpainful and painful stimuli. They studied these responses in a group of 15 children and adolescents with chronic migraines (10 to 15 years of age) and compared them with responses from a control group of migraine-free children and adolescents. The groups did not differ significantly on measures of age, family size, school type, anxiety or depression. They also found no differences between groups on early somatosensory ERPs including differences in habituation to experimental stimuli. However, they did find that children with migraines had significantly larger and earlier brain responses to painful and nonpainful mechanical stimuli. The ERP component measured (P300) has been demonstrated to be a valid and reliable reflection of attentional function. More specifically, Zohsel et al (15) suggested that their findings could point to difficulties their participants had in directing their attention away from painful stimuli as well as decreased activation of pain inhibition processes. Of note, this enhancement was limited only to mechanosensory stimuli and not toward auditory stimuli. Overall, they concluded that the children with migraines may have experienced altered attentional processing toward stimuli signalling pain. Given the small sample size and the restriction of this study to children with migraines in a specific age range, it is difficult to generalize the findings to a broader chronic pain population. However, this well-designed study does provide strong biological evidence of changes in cognitive function that may be associated with chronic headache pain.

Another study may shed some light on the effects reported by Zohsel et al (15). Buodo et al (16) found that an early electrophysiological brain component associated with selective attention was attenuated in a group of 18 children with migraines compared with matched controls. They also found that the reduction of that component was directly associated with the chronicity of migraines. They noted that their data could suggest that their study population experienced attentional disturbance when actively completing tasks and during preattentive processing of information. This suggests that attention was disrupted during the brain's early processing of information, at stages before children were actively attending to tasks. As with the Zohsel et al study (15), the size and nature of the clinical problems studied make these results difficult to generalize to a broad pediatric chronic pain population. Notwithstanding these limitations, this well-designed study also supports the proposal that chronic pain negatively affects cognitive function.

In summary, these two references are the only published studies outlining physiological measures of cognitive function in children. They examined attentional function and provided important evidence of changes in brain activity associated with a chronic pain condition. As has been found previously in ERP studies in adult chronic pain populations, they suggest that impairments in attention exist such that children with chronic pain have difficulty attending to nonpain information and are less able to disengage attention from painful stimuli. It is presently difficult to generalize the results of these studies to other chronic pain populations because they were conducted on small groups of children with migraines. Much remains to be studied regarding the specific mechanisms associated with changes in brain function in children with migraines and whether similar electrophysiological changes exist in children with other chronic pain conditions.

\section{Cognitive and academic testing}

While physiological measures provide a more microanalytic picture of the processes underlying cognitive function, work with psychological and psychoeducational testing allows one to better understand how the disrupted processes actually function in an applied context. An early study that reported analyses of cognitive function in children with chronic pain conditions shed some light on the topic. Sherry et al (17) reported on a study that examined intelligence quotient (IQ) in a sample of children and adolescents with musculoskeletal pain of unknown 
organic origin. Sixty-two of the 100 participants studied underwent IQ testing. All individuals tested were found to have fullscale IQs in the average range. Seven of the 62 participants were reported to have low academic achievement scores but no specific information was provided about academic achievement levels. Overall, the findings of Sherry et al suggest that there is no reason to believe that children and adolescents with chronic pain are at increased risk of having global intellectual deficits. There are some limitations to the conclusions that can be drawn from this study due to the study design and the method used to categorize the study population. Individuals in this study were broadly defined as having recurrent pain in the absence of clear organic etiology. Also, there is a lack of information provided by the authors regarding the reasoning for why some participants underwent cognitive testing while others did not. This risk of bias makes the generalizability of some of their conclusions tenuous, even within their own study population.

Haverkamp et al (18) examined general cognitive function in a small group $(n=37)$ of children with migraines and compared their performance on measures of sequential and simultaneous information processing with a smaller group $(n=17)$ of migraine-free siblings. They found no difference between the two groups. This study was limited by a number of factors including the size and nature of the sample, and the narrow scope of cognitive abilities assessed by the selected tests. As well, no information was included regarding pain levels during testing or school attendance data. As a result, it is somewhat difficult to evaluate chronic pain's effects on cognition and function from their findings as reported.

Further supporting the notion that pediatric chronic pain patients do not have global intellectual/intelligence deficits was a study by Ho et al (19). They used standardized tests to examine general intelligence and also school performance in a group of children and teens with chronic pain. A battery of tests measured general intellectual function (IQ) and academic levels in the domains of reading, writing, mathematics and spelling. Overall, their study population achieved above-average scores on tests of general intelligence as well as on verbal, performance and processing speed subscales. Scores from a subscale measure of working memory fell in the average range. On academic tests, the participants were found to have scores in the average range and were above average at a group level on tests of word reading and mathematical reasoning. It is worth noting that working memory function was a relative weakness for them, given similar findings of working memory problems in the adult literature (6). This study was limited by the fact that it was retrospective in nature and examined findings from cognitive testing over an extended period of time. This resulted in different tests and different versions of tests being administered between participants over the years covered in the testing sample. As well, no data were reported on school absence rates in these children. No analyses were reported that examined any relationship between current pain level and performance on cognitive tests.

In summary, it is critical to emphasize that, while some have suggested that cognitive deficits in individuals with chronic pain are a reflection of general intellectual deficits or dysfunction that existed before pain onset, there is no evidence of this. Overall, the work using standardized psychological measures of general intelligence demonstrated that children with chronic pain are functioning either at or above age expectations on those tests. These studies suggest that children's cognitive dysfunction in this population is not related to general intellectual deficits. It is important to note that there are factors related to the design and reporting of such studies that limit the extent to which we are able to make conclusions about the nature and degree of cognitive dysfunction in the children in those studies. For example, little information was provided regarding the conditions in which the cognitive tests were administered. Generally, such tests are provided in optimal circumstances, unlike the typical learning environment in a busy classroom. As well, testing procedures are generally scheduled and conducted to minimize fatigue and fatigue-related performance decrements. It is not uncommon for individuals with health problems to perform at higher levels in such circumstances compared with a school environment. Moreover, the data are based on smaller sample sizes and, thus, generalizability may be more limited. Finally, there are so few studies that have been published to date on this important topic that firm conclusions are difficult to draw at present.

\section{Self- and proxy-reports of cognitive/academic disruption} With the exception of the studies presented above by Zohsel et al (15) and Ho et al (19), we could not find studies that quantified the extent of general cognitive disruption in a pediatric population with chronic pain. However, some pertinent information is available in one publication on subjective reports of disruption. Bell et al (20) presented their findings in a small group of children with fibromyalgia. Using a $10 \mathrm{~cm}$ visual analogue scale (VAS), the children reported high levels of muscle pain (mean 8.5/10) and cognitive dysfunction (mean $6.75 / 10$ ), along with a variety of other difficulties. The small sample size and the exclusive use of the VAS using broad questioning techniques limits the conclusions that could be drawn from the reported results to the child's own perceptions of cognitive disruption. All of the data in this study were entirely based on subjective self-report data. While those data do not provide us with additional information regarding the exact nature of the disruption, it does provide a subjective estimate of the extent of the impact that cognitive dysfunction has in this group. There is a rapidly growing literature on this problem in adults with fibromyalgia (21-23), and we urge a similar increase in the study of this topic in children and adolescents.

In addition, there was one other relevant publication that did not focus specifically on cognitive function but presented subjective impressions of impairment from both parents and adolescents. In a large, well-designed study, Logan et al (24) examined school functioning in a group of adolescents with chronic pain. Participants in the study were recruited from a chronic pain clinic at a tertiary care hospital in a major urban centre. Self-report data were collected on the adolescents' school attendance and school performance. Perceived academic competence data were also collected from the adolescents themselves, their parents and school staff. School records were also accessed to verify absences and other pertinent school-related information. Perceived school impairment was not statistically related to age, sex or other demographic measures with the exception of parent education level. The latter appeared to be associated with lower levels of school impairment. The overall findings in this group of adolescents found that $44 \%$ of students missed at least $25 \%$ of school days and 
$20 \%$ missed more than one-half of school days. Parents in that study also reported a moderate level of interference from pain on the adolescents' grades, with $44 \%$ of parents reporting that their children's grades had fallen markedly since the onset of pain. While this study provided a wealth of information related to these important measures of perceived academic interference, no corroborating objective data were provided.

In summary, numerous constructs in the psychological literature have suggested that subjective perceptions can be more influential (eg, stress, social support and level of control) in predicting actual behaviour than objective measurement of the construct. Although these studies lack external validation from objective sources about cognitive disruption, it should not be ignored that the patients themselves (and in some cases the parents) reported that chronic pain was interfering with their academic functioning (a potential proxy for cognitive processing when school attendance was not a factor). Unfortunately, information was not consistently collected across studies on pain levels or the number of school days missed. Standardizing data collection would assist authors in better contextualizing chronic pain's effects on cognitive function in children. Clinicians must be nuanced when evaluating subjective perceptions of cognitive disruption from children with chronic pain.

\section{Cognitive tests of biases of attention and memory}

Because there are so few data available regarding the effects of chronic pain on cognitive function in children, it would also be expected that few data are available on the mechanisms involved in this effect. A few studies provide helpful information regarding processes that may underlie cognitive dysfunction in children. For example, Boyer et al (25) reported that children with recurrent abdominal pain showed an unconscious attentional bias toward pain-related words. Children with pain had more difficulty disengaging their attention away from pain-related words compared with neutral words. Of note, these attentional biases were associated with symptom severity. Koutantji et al (26) also found a memory bias toward painrelated information in children with juvenile arthritis in that they had a disproportionately better memory for pain-related words. While these publications do add helpful information regarding cognitive biases toward pain-related information, their findings add relatively little to a discussion of cognitive dysfunction.

In summary, these studies provide some helpful insight into changes that occur in cognitive processing of information in children with chronic pain conditions. It appears that having chronic pain may prime individuals to process pain-related information more readily. Unfortunately, these studies did not mention whether or how pain chronicity plays a role in these changes.

\section{DISCUSSION}

After an extensive search for publications that targeted cognitive function in children, no published reviews were found and only nine studies directly examined cognitive function in children and adolescents with chronic pain. While a number of studies focused on academic performance and school attendance as measures of interest, the methodologies used to examine these factors were highly variable in the studies discussed in this review, as well as in excluded studies. Only nine studies had a link to cognitive function in this population. That three of these nine studies were relatively recent publications demonstrates growing interest on this topic. Notwithstanding this small recent surge of publications, it is very surprising that so little research has been performed on a topic with such relevance to a child's short- and long-term developmental trajectories.

The studies that focused on applied areas of cognitive function (through standardized testing) provided us with particularly valuable information about factors such as the general intelligence level of children with chronic pain. These studies highlighted that the development of a chronic pain syndrome is not associated with lower general intelligence. While such a statement appears obvious to many who work with this population, it is unfortunately necessary to emphasize this fact again here. At the same time, obtaining high scores on standardized tests in a controlled testing environment may not reflect an individual's actual performance in a school setting and in their general daily function. What is clear from published reports and clinical presentations of these children is that cognitive and academic disruption is a very frustrating facet of living with chronic pain. Moreover, more work must be done to clarify the roles that personality factors (such as perfectionism) and cognitive disruption play in pediatric chronic pain patients' low perceived academic competence.

A multitude of chronic pain conditions precludes the feasibility of conducting cognitive function testing with each distinct clinical subpopulation. Thus, work with prevalent populations (such as pediatric migraine patients) does provide a good starting point for our process of understanding. In particular, current studies point to how altered central mechanisms in individuals with chronic pain syndromes can be manifested as changes in cognitive function in preattention, attention and disinhibition of attentional processes. Researchers in this area discuss the possibility of a biologically driven, involuntary vicious cycle whereby increased pain sensitivity, including increased attentional vigilance toward painful stimuli, could enhance the risk of further attentional disruption $(27,28)$. While this work was performed in migraine patients, it is quite possible that such a process affects individuals with other chronic pain syndromes by extension. Much remains to be studied on this question.

It is also worth noting that the adult literature on the disruptive effects of chronic pain on cognition also began with a foundation of studies based on subjective reporting of cognitive disruption (29) and has resulted in a much larger body of literature that has studied this effect $(6,30,31)$. In fact, in a relatively recent adult study of cognitive dysfunction in people with fibromyalgia, pain accounted significantly for the level of cognitive disruption, while other factors such as depression and sleep disruption did not (21).

In addition to the immediate importance of the impact of chronic pain on a child's cognitive function and development, it is very important to also consider the potential long-term cost to society associated with this effect. Logan et al (24) provide a pertinent and concise discussion of this issue. They highlight the fact that children with elevated school absence rates are at risk to miss out on important learning opportunities and place a child at increased risk for adjustment difficulties. It stands to reason that missing $20 \%$ to $50 \%$ of school days has the potential to dramatically affect cognitive and social skill development. 
Increasingly, brain imaging techniques are being used to study cognitive function in individuals with chronic pain. Very little such research has been performed in children and adolescents. However, there is a growing body of adult research finding that individuals with chronic pain have decreased brain volumes $(32,33)$. While none of these studies point to a specific physiological process related to reduced brain volumes, the accumulating data cannot be ignored when trying to understand how chronic pain affects cognitive function. If chronic health problems including chronic pain are associated with brain degeneration, this could be a particularly important factor in a child's developing brain. Much remains to be studied on this issue in individuals across the lifespan.

\section{Future research directions}

One possible reason for the lack of data on this critical topic is the methodological difficulties inherent in studying the effects of chronic pain on a child's cognitive function. This is

\section{REFERENCES}

1. Perquin CW, Hazebroek-Kampschreur AA, Hunfeld JA, et al. Pain in children and adolescents: A common experience. Pain 2000;87:51-8.

2. Eccleston C, Clinch J. Adolescent chronic pain and disability: A review of the current evidence in assessment and treatment. Paediatr Child Health 2007;12:117-20.

3. Palermo T. Impact of recurrent and chronic pain on child and family daily functioning: A critical review of the literature. J Dev Behav Pediatr 2000;21:58-69.

4. Zeltzer L, Bursch B, Walco G. Pain responsiveness and chronic pain: A psychobiological perspective. J Dev Behav Pediatr 1997;18:413-22.

5. Bursch B, Joseph MH, Zeltzer LK. Pain-associated disability syndrome. In: Schechter NL, Berde CB, Yaster M, eds. Pain in Infants, Children and Adolescents, 2nd edn. Philadelphia: Lippincott, Williams \& Wilkins, 2002:841-8.

6. Dick BD, Rashiq S. Disruption of attention and working memory traces in individuals with chronic pain. Anesth Analg 2007;104:1223-9.

7. Dell'Api M, Rennick J, Rosmus C. Childhood chronic pain and health care professional interactions: Shaping the chronic pain experiences of children. J Child Health Care 2007;11:269-86.

8. Eccleston C, Jordan A, Crombez G. The impact of chronic pain on adolescents: A review of previously used measures. J Pediatr Psychol 2006;31:684-97.

9. Sato AF, Hainsworth KR, Khan KA, Ladwig RJ, Weisman SJ, Davies WH. School absenteeism in pediatric chronic pain: Identifying lessons learned from the general school absenteeism literature. Child Health Care 2007;36:355-72.

10. Stang PE, Osterhaus JT. Impact of migraine in the United States: Data from the National Health Interview Survey. Headache 1993;33:29-35.

11. Geist R, Grdisa V, Otley A. Psychosocial issues in the child with chronic conditions. Best Pract Res Clin Anaesthesiol 2003;17:141-52.

12. Shapiro BS, Dinges DF, Orne EC, et al. Home management of sickle cell-related pain in children and adolescents: National history and impact on school attendance. Pain 1995;61:139-44.

13. Kearney CA. School refusal behavior in youth. Washington, DC: American Psychological Association, 2001.

14. Robinson RR. There is no shame in pain: Coping and functional ability in adolescents with sickle cell disease. J Black Psychol 1999;25:336-55.

15. Zohsel K, Hohmeister J, Flor H, Hermann C. Altered pain processing in children with migraine: An evoked potential study. Eur J Pain 2008;12:1090-101.

16. Buodo G, Palomba D, Sarlo M, Naccarella C, Battistella PA. Auditory event-related potentials and reaction times in migraine children. Cephalalgia 2004;24:554-63. at least partly due to the many factors that could affect a child's cognitive performance. While it would be difficult to account for all related factors, this does not mean that meaningful data cannot be obtained on the critical question of how chronic pain affects a child's cognitive function. Carefully planned studies that examine general cognitive function, academic performance, days missed, workload, pain chronicity, and behavioural and physiological measures of function hold the potential to provide us with a great deal of important information on this subject. In addition, there was considerable variability across studies in how pain levels in research participants were recorded. More standardized measurement based on common metrics would greatly improve the generalizability of future studies. Better understanding of those important factors will hopefully result in information that will help us understand how to reduce the impact of chronic pain on cognitive function and schooling in children and adolescents.
17. Sherry DD, McGuire T, Mellins E, Salmonson K, Wallace CA, Nepom B. Psychosomatic musculoskeletal pain in childhood: Clinical and psychological analyses of 100 children. Pediatrics 1991;88:1093-9.

18. Haverkamp F, Hönscheid A, Müller-Sinik K. Cognitive development in children with migraine and their healthy unaffected siblings. Headache 2002;42:776-9.

19. Ho GHY, Bennett SM, Cox D, Poole G. Brief report: Cognitive functional and academic achievement in children and adolescents with chronic pain. J Pediatr Psychol 2008;34:311-6.

20. Bell DS, Bell KM, Cheney PR. Primary juvenile fibromyalgia syndrome and chronic fatigue syndrome in adolescents. Clin Infect Dis 1994;18(Suppl 1):S21-3.

21. Dick BD, Verrier MJ, Harker KT, Rashiq S. Disruption of cognitive function in fibromyalgia syndrome. Pain 2008;139:610-6.

22. Leavitt F, Katz RS. Distraction as a key determinant of impaired memory in patients with fibromyalgia. J Rheumal 2006;33:127-32.

23. Park DC, Glass JM, Minear M, Crofford LJ. Cognitive function in fibromyalgia patients. Arthritis Rheum 2001;44:2125-33.

24. Logan DE, Simons LE, Stein MJ, Chastain L. School impairment in adolescents with chronic pain. J Pain 2008;9:407-16.

25. Boyer MC, Compas BE, Stanger C, et al. Attentional biases to pain and social threat in children with recurrent abdominal pain. J Pediatr Psychol 2006;31:209-20.

26. Koutantji M, Pearce SA, Oakley DA, Feinmann C. Children in pain: An investigation of selective memory for pain and psychological adjustment. Pain 1999;81:237-44.

27. Kitaj MB, Klink M. Pain thresholds in daily transformed migraine versus episodic migraine headache patients. Headache 2005;45:992-8.

28. Mathew NT, Kailasam J, Seifert T. Clinical recognition of allodynia in migraine. Neurology 2004;63:848-52.

29. Jamison RN, Sbrocco T, Parris WCV. The influence of problems with concentration and memory on emotional distress and daily activities in chronic pain patients. Int J Psychiatry Med 1988;18:183-91.

30. Eccleston C. Chronic pain and distraction: An experimental investigation into the role of sustained and shifting attention in the processing of chronic persistent pain. Behav Res Ther 1995;33:391-405.

31. Hart RP, Martelli MF, Zasler ND. Chronic pain and neuropsychological functioning. Neuropsychol Rev 2000;10:131-49.

32. Apkarian AV, Sosa Y, Sonty S, et al. Chronic back pain is associated with decreased prefrontal and thalamic gray matter density. J Neurosci 2004;24:10410-5.

33. Schmidt-Wilcke T, Leinisch E, Gänssbauer S, et al. Affective components and intensity of pain correlate with structural differences in gray matter in chronic back pain patients. Pain 2006;125:89-97. 


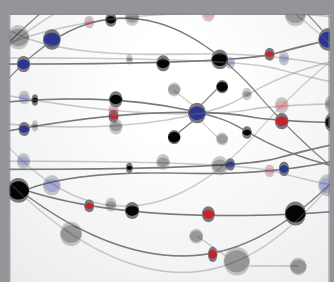

The Scientific World Journal
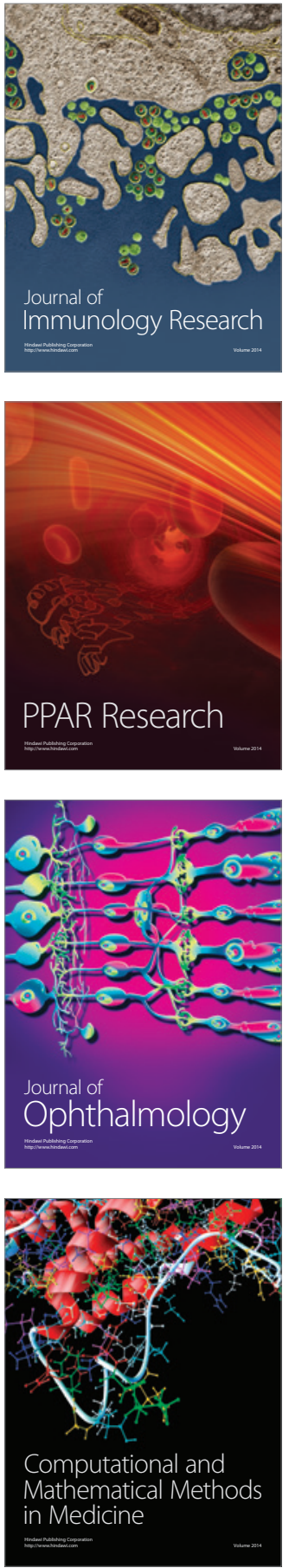

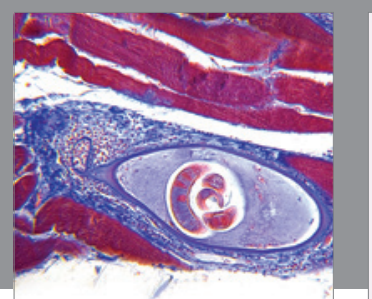

Gastroenterology Research and Practice

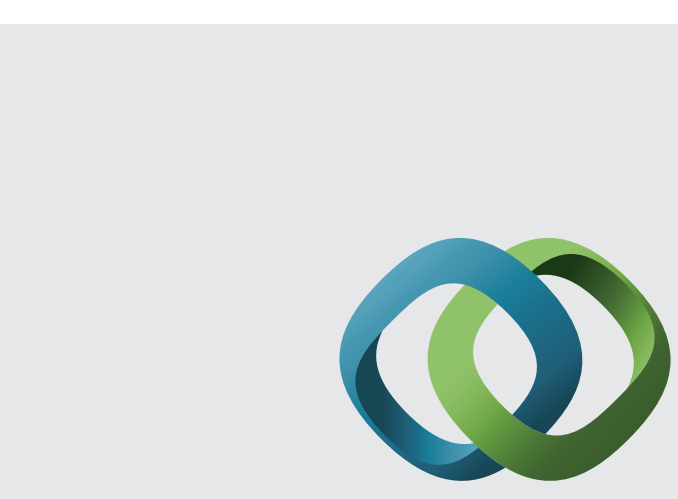

\section{Hindawi}

Submit your manuscripts at

http://www.hindawi.com
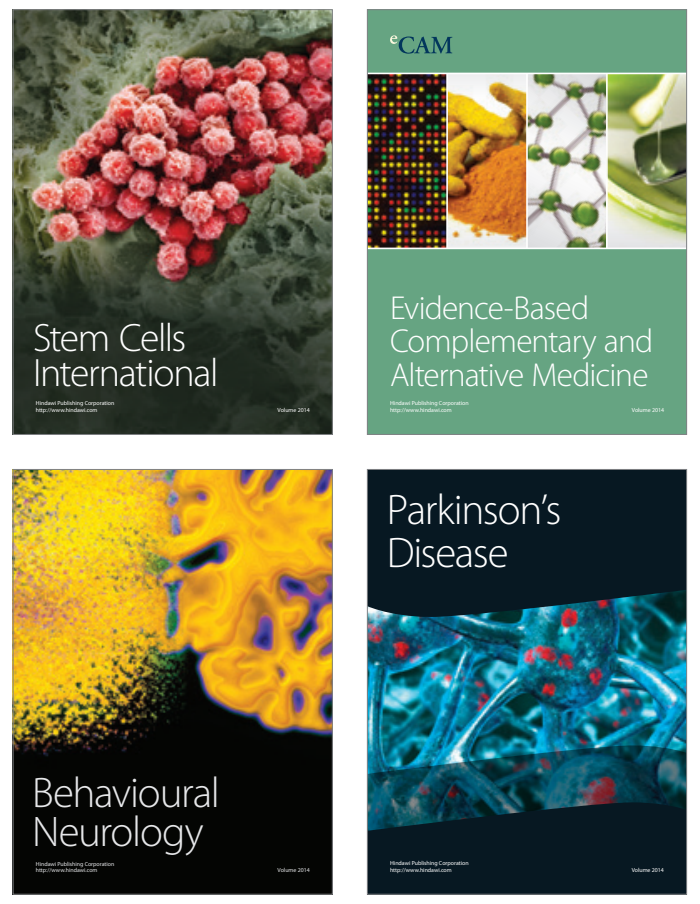
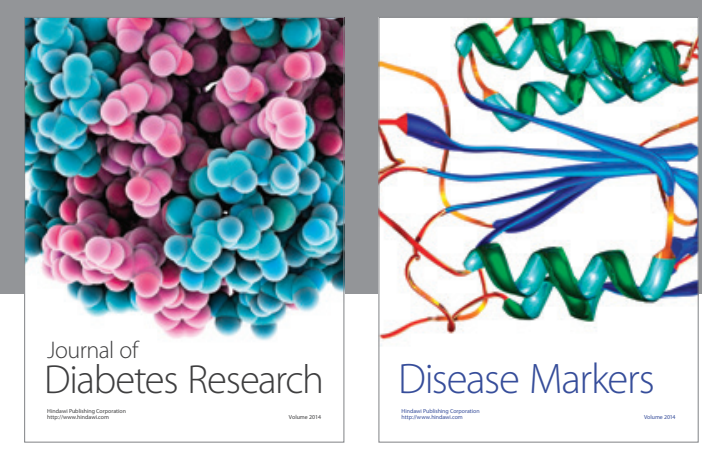

Disease Markers
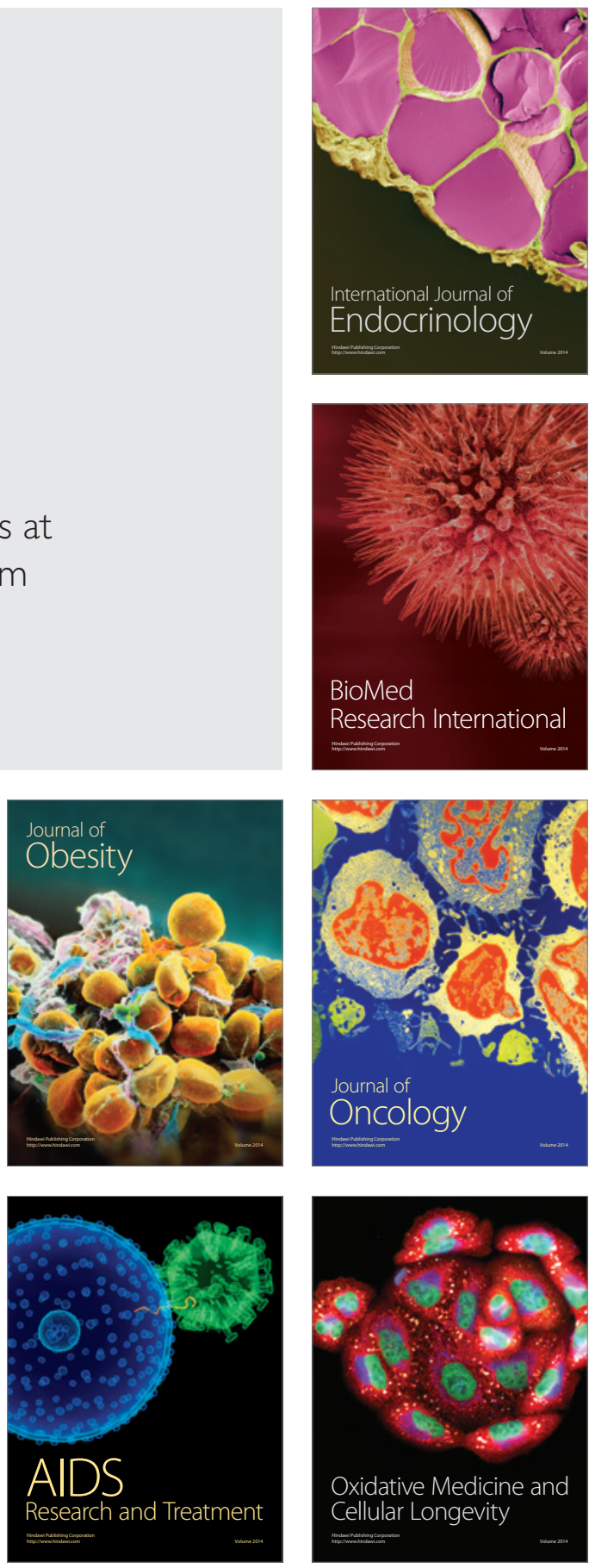